\title{
Factors affecting breastfeeding practices among working women in Pakistan
}

\author{
J.A. Soomro ', Z.N. Shaikh', S.A. Bijarani ${ }^{7}$ and T.B. Saheer ${ }^{3}$
}

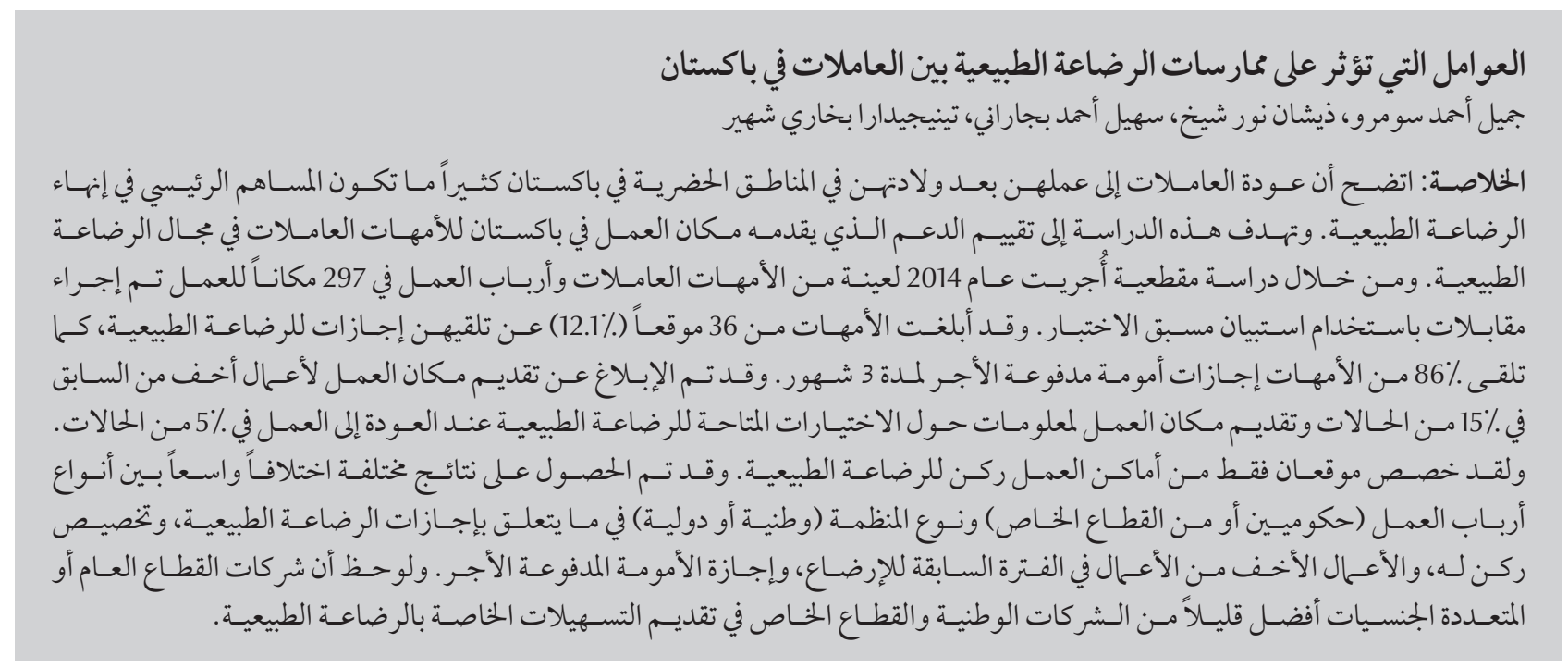

ABSTRACT In urban areas of Pakistan, women's return to work after giving birth has frequently been found to be a main contributor to the early termination of breastfeeding. This study aimed to assess workplace breastfeeding support provided to working mothers in Pakistan. In a cross-sectional survey in 2014, mothers and employers from a representative sample of 297 workplaces were interviewed using a pre-tested questionnaire. Mothers from 36 (12.1\%) sites reported receiving breastfeeding breaks, and $86 \%$ of the mothers had received 3 months paid maternity leave. Provision of a lighter job and information about breastfeeding options on return to work were reported from $15 \%$ and $5 \%$ of the workplaces, respectively. Only two sites had designated breastfeeding corners. Significantly different results were found between types of employer (government or private) and type of organization (national or multinational) with regard to breastfeeding breaks, breastfeeding corners, lighter jobs and paid maternity leave. Public and multinational companies were slightly better than private and national ones in providing breastfeeding facilities.

\section{Facteurs affectant les pratiques d'allaitement parmi les femmes actives au Pakistan}

RÉSUMÉ Dans les zones urbaines du Pakistan, le retour des femmes au travail après un accouchement contribue très souvent à l'arrêt précoce de l'allaitement. La présente étude avait pour objectif d'évaluer les conditions favorables à I'allaitement au travail pour les mères actives au Pakistan. Au cours d'une étude transversale réalisée en 2014, des mères et des employeurs issus d'un échantillon représentatif de 297 lieux de travail ont été interrogés sur la base d'une questionnaire préalablement testé. Les mères travaillant sur 36 lieux de travail (12,1\%) ont rapporté que des pauses étaient aménagées pour qu'elles puissent allaiter, et 86 \% des mères ont bénéficié d'un congé maternité payé de 3 mois. La possibilité d'un travail allégé et la mise à disposition d'informations sur les options existantes pour l'allaitement après un retour au travail étaient rapportées dans $15 \%$ et $5 \%$ des lieux de travail respectivement. Seuls deux lieux de travail disposaient d'un espace dédié à l'allaitement. Des résultats significativement différents ont été obtenus selon les types d'employeurs (gouvernement ou privé) et d'organisations (nationales ou multinationales) concernant les pauses aménagées pour l'allaitement, les espaces mis à disposition à cette fin, un travail allégé et les congés maternités payés. Les entreprises publiques et multinationales se sont révélées légèrement meilleures que les entreprises privées et nationales dans la mise à disposition d'un environnement propice à l'allaitement.

${ }^{7}$ Department of Community Medicine, Isra University, Hyderabad, Pakistan (Correspondence to: J. A. Soomro: jamiljan197@hotmail.com). ${ }^{2}$ Department of Community Medicine, Dow University of Health Sciences, Karachi, Pakistan. ${ }^{3}$ Department of Nursing and Health Promotion, Oslo and Akershus University College, Oslo, Norway.

Received: 07/07/15; accepted: 02/08/16 


\section{Introduction}

Breastfeeding is an important measure in safeguarding children's health and survival (1). In Pakistan it is estimated that 78 out of every 1000 live-born children die before their first birthday (2). According to the United Nations Children's Fund (UNICEF), 16\% of infant deaths could be prevented by breastfeeding from birth (2). From 1983 to 2008, the percentage of women in Pakistan who breastfed for up to one year declined from $96 \%$ to $31 \%$ (3). Workplace barriers have been reported as one of the major reasons for early cessation of breastfeeding by working mothers (3-6). Returning to work has frequently been found to be a main contributor to the early termination of breastfeeding $(7,8)$. Many mothers who return to work stop or reduce breastfeeding because they do not have enough time or an appropriate place to breastfeed or express and store their breast milk (7-9). Studies indicate that mothers who have easy access to their baby during the working day, or who can express breast milk at work, breastfeed their babies for longer than those who do not have such access (9,10). A supportive environment, such as paid maternity leave, part-time work engagements, facilities for expressing and storing breast milk at work, breastfeeding breaks and national legislation on breastfeeding support at work have resulted in a higher prevalence and longer duration of breastfeeding $(7,10)$.

For employers, the benefits of providing a working environment favourable to breastfeeding outweigh the costs. If breastfeeding is supported in the workplace, women are more likely to return to work earlier after giving birth, which contributes to women preserving their job skills, as well as reducing staff turnover (11-13). A survey in Hong Kong Special Administrative Region of China showed that $26 \%$ of workplaces had allocated a separate room for breastfeeding, and only 11\% of hospitals allowed employees to take breaks as needed to use a breast pump (14).

Several studies have reported the importance of national legislation in supporting breastfeeding practices at work $(10,13,14)$. One study noted that "policies can validate the employees' right to provide their milk for their children, even when individual supervisors or co-workers are less than supportive" (14). In Pakistan, the lack of legislation (other than that providing for three months' paid maternity leave) in support of working mothers breastfeeding at work may be a contributing factor to the non-adherence of employers to international guidelines (3).

A qualitative study in Pakistan reported workplace barriers as one of the main reasons for early cessation of breastfeeding among working mothers (15). However, there has been little research into workplace breastfeeding facilities. The current study examines the status of the available breastfeeding facilities in Pakistan with a view to obtaining insights that could be useful to decision-makers.

\section{Methods}

\section{Study design and sampling}

A cross-sectional survey was conducted in 2014 on 297 workplaces, randomly selected from 2983 registered sites in Karachi, Pakistan. Karachi has a population of around 23.5 million, making it the largest city of Pakistan (16). The population of the city includes almost every socioeconomic class and ethnic group living in Pakistan. Additionally, it is home to Pakistan's major business activities and a hub of higher education (16). All workplace sites registered with appropriate government authorities, i.e. hospitals, banks, factories and schools, were considered as the relevant study population (17-20).
At each selected site, one employer and one mother were interviewed. The employer was a manager or officer representing the workplace unit. Mothers were included if they were 3-24 months postpartum, had initiated breastfeeding prior to the survey, and at the time of the interview had returned to the job they had before giving birth. The mothers were selected purposively.

It was assumed that some employers in the randomly selected sample ( $n$ $=296$ ) would refuse to take part in the study. Therefore, $7 \%$ extra workplaces were included in the initial sample. A final sample of 297 sites was achieved; ten sites were found not to be eligible, while eight employers refused to participate in the study. Female research assistants were trained to invite participants for the interview, to conduct the interview and to complete the questionnaire. The participants were given a sheet that contained information about the survey and contact details of the principal investigator. The research assistants were trained to explain the nature of the research, why the participant had been chosen, and her or his right to refuse to participate or to withdraw from the survey at any time.

The study was approved by the institutional review board of the Dow University of Health Sciences, Pakistan, and the South-Eastern Regional Ethical Committee of Oslo, Norway.

\section{Data collection}

The structured questionnaire was designed in English and Urdu based on guidelines of the World Alliance for Breastfeeding (21). The questionnaire was pretested in eight workplace sites, with equal representation of public and private enterprises. Subsequently, some changes were made to the survey's language and style to improve its comprehensibility.

The questionnaire comprised two sections. The first section enquired about sociodemographic characteristics of the workplace: site level (national 
versus multinational), job site (bank, school, hospital or factory) and type of employer (government, private, selfemployed). Because the study focused on assessing workplace breastfeeding facilities, identifying information for the workplace, such as the name and address of the site, and personal details of the employer and the mother were not collected to avoid potential ethical issues,.

The second section enquired about breastfeeding facilities, such as whether there were breastfeeding breaks, a breastfeeding corner, a place to store breast milk, a crèche or nursery at the workplace, paid maternity leave, possibility of moving to a lighter job, and options to facilitate breastfeeding (parttime work, extension of maternity leave or change of shift). Responses were yes or no. Mothers and employers were considered the persons in a workplace most likely to know about the availability of breastfeeding facilities. The employers and mothers from each site were interviewed using the same questionnaire, to enhance the confidence of the quality of our findings.

\section{Statistical analysis}

The data were analysed on Stata version 13 and SPSS version 22. All the variables were categorical. Descriptive statistics were computed by running frequencies and cross-tabulations on SPSS to obtain percentages and confidence intervals. Differences were considered statistically significant when $P<0.05$. Charts were also developed using graph and chart builder.

Stata version 13 was used to compare proportions. Differences in proportions of breastfeeding facilities, with 95\% confidence intervals $(\mathrm{CI}$ ), were examined by type of respondent (mother or employer) type of employer (government or private) and site level (national or multinational). For the comparison by type of employer and site level, we used the mothers' responses.

\section{Results}

A total of 594 participants from 297 sites completed the questionnaire. Table 1 shows the characteristics of the sample. The largest groups in the sample were banks (42\%), private employers (75\%) and national-level sites (76\%). Figure 1 shows the availability of breastfeeding facilities at work according to the mothers $(n=297)$. Paid maternity leave was provided in most of the workplaces (86\%). Only $15 \%$ of the sites provided mothers with a lighter or safer job while they were lactating. It was observed that most of the job assignments for female employees were fixed, with the exception of banks and schools; no other site had the possibility to relocate mothers to a site closer to their home to make breastfeeding easier. In $12 \%$ of the sites, at least one hour of paid breastfeeding breaks was offered during a work shift of 6-8 hours. Only two workplaces had a crèche on site providing child care and had designated a breastfeeding corner; none of the sites had a designated facility for storage of breast milk for later use.

The same questionnaire was used with the mothers and the employers, so that responses from the two different groups could be compared (Table 2). Altogether, $96 \%$ of the employers claimed that the mothers were provided breastfeeding breaks, compared with $12 \%$ of the mothers. The difference in

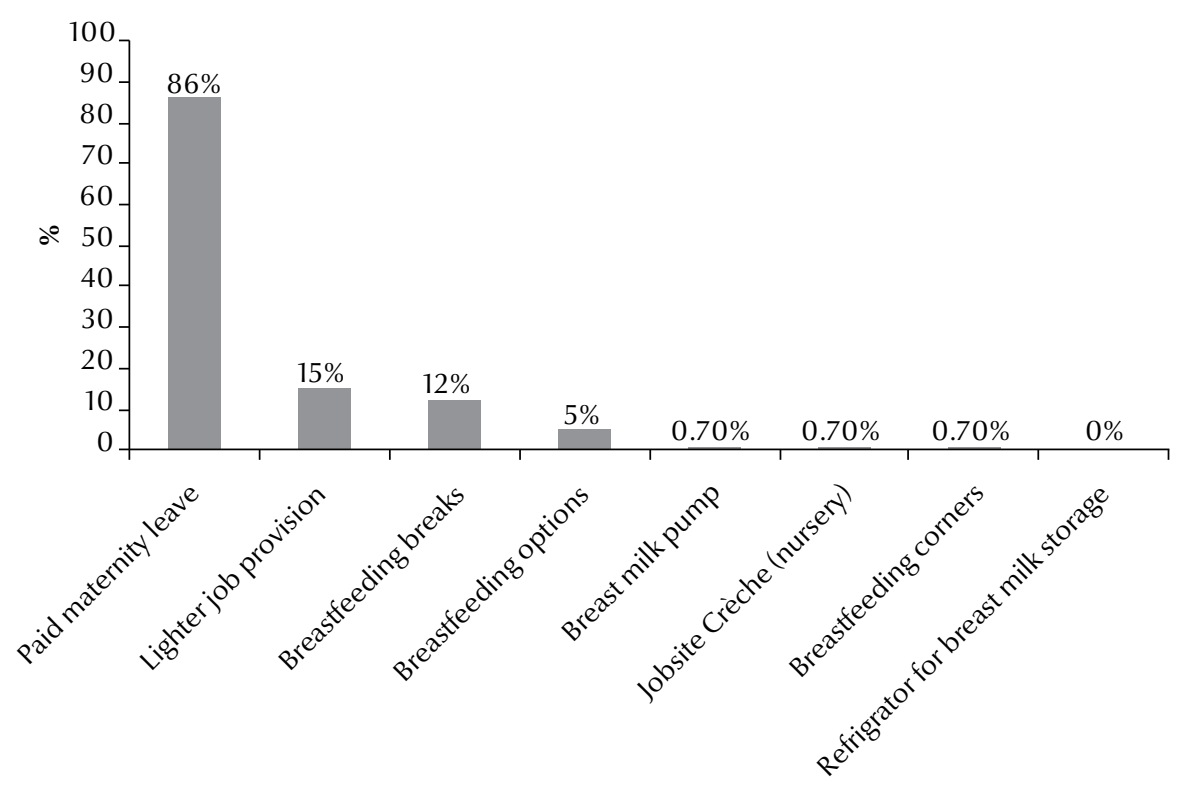

Figure 1 Provision of workplace breastfeeding facilities, according to mothers 


\begin{tabular}{lcc}
\hline Table 1 General characteristics of the sample & & \\
Characteristic & Number & Percentage \\
Total & 297 & 100 \\
Type of business & 123 & 42 \\
$\quad$ Bank & 87 & 29 \\
School & 66 & 22 \\
Factory & 21 & 7 \\
Hospital & & 50 \\
Interviewees & 297 & 50 \\
$\quad$ Mother & 297 & \\
$\quad$ Employer & & 75 \\
Type of employer & 222 & 25 \\
$\quad$ Private & 75 & 76 \\
$\quad$ Government & & 24 \\
Site level & 226 & \\
$\quad$ National & 71 & \\
$\quad$ Multinational &
\end{tabular}

proportions between employers and mothers was statistically significant. Similarly, employers overestimated non-physical breastfeeding facilities compared with mothers, such as paid maternity leave (100\% vs $86 \%$ ), availability of lighter jobs (45\% vs 15\%), and provision of breastfeeding options for mothers on their return to work, e.g. part-time work, extension of maternity leave, or change of shift ( $21 \%$ vs $5 \%)$. However, no significant difference was observed between the two groups in their responses regarding physical breastfeeding facilities, such as a breast milk pump, jobsite crèche for child care, and availability of a place for storing breast milk (refrigerator).

The status of breastfeeding facilities in the public and private sectors was compared, using the responses of the mothers only. More public workplaces than private ones were reported to provide at least three months paid maternity leave ( $99 \%$ vs $81 \%$ ). This difference was statistically significant $(P<0.001)$. Similarly, breastfeeding breaks of at least one hour in a shift of 6-8 hours were also more common in the public sector $(23 \%$ vs $9 \%)(\mathrm{P}<0.001)$. Only the mothers in the private sector $(7 \%)$ reported having breastfeeding options work, change in shift, maternity leave extension). A breastfeeding corner was provided by $1 \%$ of the government sites and none of the private sites. However, this difference was not statistically significant. No workplace had a designated place or refrigerator to store mothers' milk. A breast milk pump and jobsite crèche or nursery for child care was provided by $1.3 \%$ of the government facilities and $0.5 \%$ of the private companies; the difference was not statistically significant.

Table 3 shows the difference in proportions of workplace breastfeeding facilities between multinational and national sites. The multinational sites provided more breastfeeding facilities than the national sites and the difference was statistically significant $(P<0.001)$. The facilities included: breastfeeding breaks of at least one hour per shift ( $25 \%$ vs $8 \%$ ); at least three months paid maternity leave ( $100 \%$ vs $81 \%$ ); provision of lighter job or transfer to a safer workplace during lactation (38\% vs $8 \%$ ); provision of appropriate options to support breastfeeding at work (17\% vs $2 \%$ ). Most of the multinational sites offered more than three months paid leave. Surprisingly, none of the facilities for their return to work (part-time had allocated a place, such as a refrigerator, for working mothers to store breast milk for their babies.

\section{Discussion}

To the best of our knowledge, this is the first quantitative study in Pakistan exclusively focusing on assessment of workplace breastfeeding facilities with a large random sample. Information was obtained from two sources, mothers and their employers, using the same type of questionnaire in order to increase confidence in the findings. Our study revealed that the workplaces generally had few breastfeeding facilities. The two groups of respondents gave significantly different answers regarding non-physical facilities, such as breastfeeding breaks, maternity leave, availability of a lighter job, and provision of information about breastfeeding options. Breastfeeding support was slightly better in public and multinational sites than in private and national sites.

Mothers in $12 \%$ of the workplaces reported that they had breaks to breastfeed or express breast milk. This was similar to the findings of Dodgson et al. (11\%) (14) and Weber et al. (16\%) (22). Heymann et al. (23) found that, globally, the rate of exclusive breastfeeding of children under six months of age was $9 \%$ greater in countries that ensured paid breastfeeding breaks at workplaces. A qualitative study in Pakistan by Hirani et al. (15) also found that job flexibility and a flexible schedule at the workplace were important if working mothers were to sustain breastfeeding while employed.

However, our findings with regard to breastfeeding breaks are not consistent with those of many studies in developed countries, possibly because of the existence in those countries of workplace breastfeeding policies, lactation programmes and additional support to mothers in the form of education 


\begin{tabular}{|c|c|c|c|c|c|c|}
\hline \multirow[t]{2}{*}{ Workplace breastfeeding facilities } & \multicolumn{2}{|c|}{$\begin{array}{c}\text { Mothers responding } \\
\text { yes }\end{array}$} & \multicolumn{2}{|c|}{$\begin{array}{l}\text { Employers } \\
\text { responding yes }\end{array}$} & \multirow{2}{*}{$\begin{array}{l}\text { Test of difference } \\
\text { in proportion } \\
(95 \% \mathrm{Cl})\end{array}$} & \multirow[t]{2}{*}{$P$ value } \\
\hline & No. & $\%$ & No. & $\%$ & & \\
\hline Breastfeeding breaks & 36 & 12 & 285 & 96 & $84(80-88)$ & $<0.001$ \\
\hline Breastfeeding corners & 2 & 0.7 & 17 & 6 & $5(2-7)$ & $<0.001$ \\
\hline Breast milk pump & 2 & 0.7 & 3 & 1 & $0.03(0.01-0.081)$ & 0.653 \\
\hline Jobsite crèche for child care & 2 & 0.7 & 5 & 1.7 & $0.01(-0.02-0.07)$ & 0.254 \\
\hline Paid maternity leave & 255 & 86 & 297 & 100 & $14(10-18)$ & $<0.001$ \\
\hline Lighter job or task adjustment & 45 & 15 & 134 & 45 & $30(23-37)$ & $<0.001$ \\
\hline Breastfeeding options (part-time work, etc.) & 16 & 5 & 63 & 21 & $16(11-21)$ & $<0.001$ \\
\hline
\end{tabular}

and resources (24-28). The availability of breastfeeding corners, a breast milk pump and a place for storing breast milk (refrigerator) would allow women to feel more confident and encourage them to breastfeed $(3,29)$.

In our study, only two sites had a designated breastfeeding corner and workplace crèche for child care. These findings are similar to those of some previous studies $(14,29)$, but different from the studies by Allen et al. (25) and Bai et al. (27), which reported $70 \%$ and $80 \%$, respectively. The large difference is most likely the result of policies, programmes and awareness-raising of women by lactation consultants in those study settings, all of which are lacking in Pakistan.

Almost $86 \%$ of the mothers were given paid maternity leave for three months in our study, similar to what was found in studies in Malaysia and India $(93 \%)(29,30)$. However, the paid maternity leave cannot be compared with many other studies in countries such as Australia, Canada, China and the Islamic Republic of Iran, which offer more than three months paid or unpaid maternity leave $(9,23,31,32)$.

The finding that women in only $5 \%$ of the sites reported receiving information about breastfeeding options on their return to work is consistent with that of Weber et al. (5\%) (23). The lack of policies and lactation programmes in Pakistan limits the relevance of comparison of the findings with other studies $(25,27,28)$.

Little literature is available for comparison of the perspectives of the employer or owner on workplace breastfeeding facilities. A qualitative study in Pakistan concluded that the employer's perspective is critical for understanding and supporting breastfeeding in workplaces (15). Tan et al. reported that the employer's behaviour influences working mothers' perception of workplace breastfeeding support (33).

Employers tended to overestimate the available workplace breastfeeding facilities, possibly for fear of harming the reputation of the organization or of negatively affecting their status if the data were shared with the government. Employers may think that providing facilities for breastfeeding mothers could be financially damaging for the workplace, or that breastfeeding is a personal activity that reduces the time employees spend working. The employers may have thought that the data would be communicated to international or nongovernmental organizations, which might then put pressure on the government to take action against sites without facilities. Finally, breastfeeding facilities may be confused with other staff facilities (routine breaks over breastfeeding breaks, female common room as a breastfeeding room, etc.) $(3,33,34)$.
On the other hand, mothers may have under-reported breastfeeding facilities in order to obtain additional benefits or to attract the attention of decision-makers. Mothers may have little awareness of workplace breastfeeding rights set by labour organizations (local and international). Finally, in large workplaces, mothers may not be aware of all the available facilities, especially the less visible ones (separate rooms, separate refrigerators, etc.).

However, the two groups of respondents showed general agreement on the availability of the following breastfeeding facilities: a breastfeeding corner, a refrigerator, a breast milk pump and a nursery. This agreement may be because all these were physical facilities and could be verified. The mothers are probably the more reliable group, because of their direct interest and benefit from breastfeeding facilities.

The significant difference observed between private and public sector organizations, with regard to breastfeeding breaks, maternity leave, task adjustment and information regarding breastfeeding options, is consistent with the findings of other studies $(14,23,29)$. In Pakistan, mothers working in the public sector tend to have greater workplace breastfeeding support than those in the private sector, because of the nature of the work. The majority of banks, factories, and companies with a rigid type of job and short rest periods 


\begin{tabular}{|c|c|c|c|c|c|c|}
\hline \multirow[t]{2}{*}{ Workplace breastfeeding facilities } & \multicolumn{2}{|c|}{$\begin{array}{l}\text { Multinational } \\
\quad(n=71)\end{array}$} & \multicolumn{2}{|c|}{$\begin{array}{l}\text { National } \\
(n=226)\end{array}$} & \multirow[t]{2}{*}{$\begin{array}{l}\text { Test of difference in } \\
\text { proportion }(95 \% \mathrm{Cl})\end{array}$} & \multirow[t]{2}{*}{$P$ value } \\
\hline & No. & $\%$ & No. & $\%$ & & \\
\hline Breastfeeding breaks & 18 & 25 & 18 & 8 & $17(7-28)$ & $<0.001$ \\
\hline Breastfeeding corners & 2 & 3 & 0 & 0 & $3(1-6)$ & $<0.001$ \\
\hline Breast milk pump & 0 & 0 & 2 & 1 & $0.08(0.3-2)$ & 0.426 \\
\hline Jobsite crèche for child care & 0 & 0 & 2 & 1 & $0.08(0.3-2)$ & 0.426 \\
\hline Paid maternity leave & 71 & 100 & 184 & 81 & $19(14-24)$ & $<0.001$ \\
\hline Lighter job or task adjustment & 27 & 38 & 18 & 8 & $30(18-42)$ & $<0.001$ \\
\hline Breastfeeding options (part-time work, etc.) & 12 & 17 & 4 & 2 & $15(6-24)$ & $<0.001$ \\
\hline
\end{tabular}

are privately owned, in contrast to jobs in schools and hospitals in the government sector, which tend to be less busy. Moreover, the public sector is more likely to adopt breastfeeding-friendly policies $(14,23,29)$.

Asignificant difference was also seen between the national and multinational sectors, in the provision of breastfeeding breaks, separate rooms, maternity leave, task adjustment and information. There has been no previous study comparing breastfeeding support in national and multinational sites. The difference in our study could be related to the fact that most of the multinational companies in Pakistan have their headquarters in high-income countries that have breastfeeding policies, and this influences the employer to support working mothers $(3,23,31,35)$. Another reason could be the greater adherence to international labour laws by multinational companies than national companies in developing countries $(21,31,32)$. Meeting the needs of breastfeeding workers is best achieved when there is a clear-cut policy to address these issues. Without such a policy, these issues and the need to make changes within an organization are not brought to the attention of the employer (21,32).
There is a need for national legislation to address these problems. Without national laws or regulations, employers are not legally obliged to provide the necessary facilities at the workplace for encouraging mothers to breastfeed their infants. This legislation could be based on the WHO International Code of Marketing of Breast-Milk Substitutes (36), which aims to promote breastfeeding and enhance infants' health.

We recognize that our study had several limitations. First, it focused only on an urban area of Pakistan; the results, therefore, cannot be generalized to rural areas, which account for onethird of female workers (16). Secondly, unregistered workplaces, such as shops, small clinics and home-based businesses, were not included. Though such workplaces are small in number, they may influence the internal and external validity of our study. Thirdly, our sample was dominated by private sector companies, mainly banks and schools, and this may also have influenced our results through under-representation of the public sector and sites such as hospitals and factories. Finally, the mothers were enrolled purposively because of limited time and resources, which could have influenced the results.
Nevertheless, the study setting (Karachi) is the largest city of Pakistan and the second-largest city in the world by population size, and includes almost every social class and ethnic group living in Pakistan (16). We believe the results could be generalized to the other cities in the country, since it is likely that working mothers have similar working conditions, tasks, culture, and socioeconomic status. Our study could also serve as a baseline in specific settings, for follow-up studies to examine the impact of interventions, such as policy reform and workplace lactation programmes. Our findings could also inform future large population-based surveys in urban and rural areas, to get a clear picture of breastfeeding facilities at workplaces in Pakistan.

\section{Acknowledgements}

The authors thank Professor Per Nafstad, Department of Community Medicine, University of Oslo for his technical support throughout the study period.

Funding: The authors acknowledge the research committee at the Section for International Health, University of Oslo, Oslo, Norway for funding the study.

Competing interests: None declared. 


\section{References}

1. Breastfeeding. Geneva: World Health Organization; 2015 (http://www.who.int/topics/breastfeeding/en/, accessed 2 April 2015)

2. Media centre. Pakistan. New York: United Nations Children's Fund; 2011 (http://www.unicef.org/pakistan/media_7180. htm, accessed 3 April 2015).

3. Hirani SA, Karmaliani R. Evidence based workplace interventions to promote breastfeeding practices among Pakistan working mothers. Women Birth. 2013;26(1):10-6.

4. Pakistan Demographic and Health Survey. Islamabad and Calverton, MD: National Institute of Population Studies and ICF International; 2012-13 (http://www.nips.org.pk/abstract_files/ Priliminary\%20Report\%20Final.pdf, accessed 3 April 2015)

5. Pakistan Demographic and Health Survey. Islamabad: Nationa Institute of Population Studies and Macro International Inc: 2006-07.

6. Breastfeeding. Islamabad: Society for the Protection of the Rights of Child; 2008. (http://www.sparcpk.org/2015/Health. html accessed 8 April 2015).

7. Chatterji P, Frick KD. Does returning to work after childbirth affect breastfeeding practices?. Review of Economics of the Household. 2005; 3(3):315-35

8. Stewart-Knox B, Gardiner K, Wright M. What is the problem with breast-feeding? A qualitative analysis of infant feeding perceptions. J Hum Nutr Diet. 2003;16(4):265-73.

9. Morse JM, Bottorff JL, Boman J. Patterns of breastfeeding and work: the Canadian experience. Can J Public Health. 1989;80(3):182-8.

10. Auerbach KG, Guss E. Maternal employment and breastfeeding. A study of 567 women's experiences. Am J Dis Child. 1984;138(10):958-60.

11. Brown CA, Poag S, Kasprzycki C. Exploring large employers' and small employers' knowledge, attitudes, and practices on breastfeeding support in the workplace. J Hum Lact. 2001;17(1):39-46.

12. Cohen R, Mrtek MB. The impact of two corporate lactation programs on the incidence and duration of breast-feeding by employed mothers. Am J Health Promot. 1994;8(6):436-41.

13. Cohen R, Mrtek MB, Mrtek RG. Comparison of maternal absenteeism and infant illness rates among breast-feeding and formula-feeding women in two corporations. Am J Health Promot. 1995;10(2):148-53.

14. Dodgson JE, Chee YO, Yap TS. Workplace breastfeeding support for hospital employees. J Adv Nurs. 2004;47(1):91-100.

15. Hirani SA, Karmaliani R. The experiences of urban, professional women when combining breastfeeding with paid employment in Karachi, Pakistan: a qualitative study. Women Birth. 2013;26(2):147-51.

16. Government of Pakistan. Labour force survey 2012-2013. Islamabad: Pakistan Bureau of Statistics; 2013 (http://www.pbs. gov.pk/content/labour-force-survey-2012-13-annual-report, accessed 10 April 2015).

17. Pakistan Medical and Dental Council, 2013 (http://www pmdc.org.pk/Allrecognizedinstitutes/tabid/340/Default. aspx, accessed February 2014).

18. State Bank of Pakistan. 2013 (http://www.sbp.org.pk/, accessed February 2014)

19. The Company Law Division. Securities and Exchange Commission of Pakistan (https://www.secp.gov.pk/companyformation/starting-a-company/company-name-reservation/, accessed February 2014).
20. Education \& Literacy Department. Government of Sindh Pakistan (http://www.sindheducation.gov.pk/home/index.jsp accessed February 2014)

21. Maternity protection (MP) campaign kit. 2nd ed. Penang: World Alliance for Breastfeeding Action; 2008 (http://www. waba.org.my/whatwedo/womenandwork/mpckit.htm, accessed 14 February 2014)

22. Weber D, Janson A, Nolan M, Wen LM, Rissel C, Weber D et al. Female employees' perceptions of organizational support for breastfeeding at work: findings from an Australian health service workplace. Int Breastfeed J. 2011;6(1):1-7.

23. Heymann J, Raub A, Earle A. Breastfeeding policy: a globally comparative analysis. Bull World Health Organ. 2013;91(6):398-406.

24. Bai DL, Fong DY, Tarrant M. Factors associated with breastfeeding duration and exclusivity in mothers returning to paid employment postpartum. Matern Child Health J. 2015;19:990-9.

25. Allen JA, Belay B, Perrine CG. Using mPINC data to measure breastfeeding support for hospital employees. J Hum Lact. 2014;30(1):97-101.

26. Dixit A, Feldman-Winter L, Szucs KA. "Frustrated", "depressed" and "devastated" pediatric trainees: US academic medical centers fail to provide adequate workplace breastfeeding support. J Hum Lact. 2015; 31:240-8.

27. Bai YK, Gaits SI, Wunderlich SM. Workplace lactation support by New Jersey employers following US Reasonable Break Time for Nursing Mothers law. J Hum Lact. 2015;31(1):76-80.

28. Joy R, Baker E. Breastfeeding practices of paediatrician mothers: Do we practice what we preach. Arch Dis Child. 2014;99(Suppl 1):A89 (http://adc.bmj.com/content/99/Suppl_1/A89.2, accessed 24 October 2016).

29. Amin RM, Said ZM, Sutan R, Shah SA, Darus A, Shamsuddin K. Work related determinants of breastfeeding discontinuation among employed mothers in Malaysia. Int Breastfeed J. 2011;6(1):4

30. Kumar V, Arora G, Midha IK, Gupta YP. Infant and young child feeding behaviors among working mothers in India: implications for global health policy and practice. Int J MCH AIDS. 2015;3(1):7-15.

31. Atabay E, Moreno G, Nandi A, Kranz G, Vincent I, Assi TM et al. Facilitating working mothers' ability to breastfeed: global trends in guaranteeing breastfeeding breaks at work, 19952014. J Hum Lact. 2015;31(1):81-8.

32. International Labour Organization. Maternity at work: A review of national legislation. Findings from ILO database of conditions of work and employment laws. Geneva: International Labour Office; 2012 (www.ilo.org/global/standards/lang--en/ index.htm, accessed February 2014)

33. Chow T, Smithey Fulmer I, Olson BH. Perspectives of managers toward workplace breastfeeding support in the state of Michigan. J Hum Lact. 2011;27(2):138-46.

34. Hirani SA, Karmaliani R. Breastfeeding support for working mothers: Global and Pakistani perspectives. Curr Pediatr Rev. 2012;8(4):313-21.

35. Ip S, Chung M, Raman G, Chew P, Magula N, Devine D et al. Breastfeeding and maternal and infant health outcomes in developed countries. Evid rep technol assess. 2007; (153):1-186.

36. International code of marketing of breast-milk substitutes. Geneva: World Health Organization; 1981 (http://apps.who.int/ iris/handle/10665/40382, accessed February 2014). 